\title{
Incertidumbre, ciclo económico y crisis según el enfoque continuista del pensamiento keynesiano
}

\author{
Juan HERNÁNDEZ ANDREU \& Guido TORTORELLA ESPOSITO \\ Universidad Complutense de Madrid \& Università degli Studi del Sannio di Benevento \\ ihandreu@ccee.ucm.es \& guidotor@unisannio.it
}

Recibido: 06/07/2014

Aceptado: 15/09/2014

\begin{abstract}
Resumen
Interpretando el pensamiento económico keynesiano según un planteamiento continuista entre el Tratado de la Moneda y la Teoría General, este artículo repasa el pensamiento postkeynesiano y estudia la influencia ejercida por los cambios en las economías occidentales a partir de los años de mil novecientos ochenta - como fueron los de la desregulación del mercado de trabajo, de la desregulación del mercado financiero y del fenómeno de las concentraciones empresariales -mediante proceso recesivo de la economía que llega a la crisis actual.
\end{abstract}

Palabras clave: postkeynesianismo, continuismo en Keynes, incertidumbre, ciclos económicos, crisis actual

Uncertainty, economic cycles and economic crises according to the continuism approach of Keynesian thought

\begin{abstract}
This article revisits the post-Keynesian thought considering Keynes to have a continuism approach, that it to say, assuming that there is no break between A Treatise on Money and The General Theory. It studies the influence on economics of the changes which have taken place in Western economies from the 1980's - the deregulation of the labor market, the deregulation of financial markets and the business concentration phenomenon - within the recessive process of the economy persisting in the current crisis. Key words: post-keynesianism, continuism in Keynes, uncertainty, economic cycles, current crisis.

Sumario: Introducción. 1. Interpretación discontinuista y continuista del pensamiento de Keynes 2. Los problemas empíricos y los imperativos ontológicos y metodológicos de Keynes. 3. Deuda privada y crisis económica según la teoría del circuito monetario de la escuela italiana de Augusto Graziani. 4. Conclusiones. 5. Referencias.
\end{abstract}

\section{Introducción}

La mayoría de los estudiosos del pensamiento Keynesiano interpretan el modelo de la Teoría General como una revolución científica a la Kuhn, capaz de romper radicalmente con los esquemas neoclásicos tradicionales. En este sentido, la teoría económica proporcionada en el Tratado de la Moneda parece fruto del trabajo de un economista que, atento a los hechos del contexto histórico de su tiempo, pretende 
sobrepasar los puntos críticos del modelo teórico de la escuela neoclásica marshalliana, de la que formaba parte, aunque conservando su planteamiento.

Por el contrario, hay una rama del pensamiento económico keynesiano que interpreta el pensamiento de Keynes según un planteamiento de tipo continuista. Esa rama afirma que existen buenas razones históricas y teóricas para creer que transitando del Tratado de la Moneda a la Teoría General, Keynes, después de haber explicado el funcionamiento de los ciclos del crédito y los ciclos económicos provenientes de aquellos, en un contexto de oferta de moneda endógena, entendió la exigencia de profundizar sus estudios del lado de la demanda de moneda, siendo consciente del hecho que las crisis económicas se originan, además de por otras razones, también debido a la tendencia de los operadores económicos a atesorar la moneda para defenderse contra las incertidumbres de los sistemas económicos en los que intervienen. En la Teoría General, en efecto, las principales conclusiones a las que Keynes llega con referencia a las orígenes de las crisis económicas se apoyan en las hipótesis de que el sistema económico, por su misma naturaleza, está caracterizado por la presencia de una incertidumbre permanente, y que la moneda, además de ser medio de pago, a causa de la presencia de esta incertidumbre, es también utilizada por los operadores económicos como reserva de valor (Keynes, 1937, p. 216). Por esta razón, operando en un mundo incierto, los agentes económicos sólo pueden tomar sus decisiones económicamente relevantes - como las del consumo o de la inversión - conforme su grado de confianza en el funcionamiento futuro del sistema económico, es decir según sus propias expectativas. En caso de expectativas pesimistas (pérdida de confianza en el sistema económico), las familias reaccionan incrementando sus reservas de liquidez para prepararse contra los posibles eventos futuros negativos que puedan presentarse, con el consiguiente aumento de la tasa de interés; mientras que los empresarios reaccionan reduciendo sus gastos de inversiones; (y viceversa en el caso de expectativas optimistas). Eso provoca, en el ámbito de la moneda, una contracción de la velocidad de circulación de la moneda misma, mientras que en lo real, una contracción de la demanda agregada, y entonces de la oferta agregada y de la producción, con el consiguiente aumento del paro. En este sentido, se puede afirmar que lo que verdaderamente interesa a Keynes, y entonces a los post-keynesianos, es el estudio de los efectos de las reacciones de los macro-agentes económicos - trabajadores, empresarios y bancos - a las variaciones de sus expectativas con referencia al futuro del sistema económico, fuertemente condicionado a los cambios de contexto histórico e institucional, que pueden ocurrir con el pasar del tiempo.

Partiendo de esos aspectos, en este trabajo se persigue el objetivo de estudiar la influencia ejercida por los cambios determinantes que acaecieron en las economías occidentales a partir de los años de mil novecientos ochenta - como fueron los de la desregulación del mercado de trabajo, de la desregulación del mercado financiero y del fenómeno de las concentraciones empresariales -mediante proceso recesivo de la economía que llega a la crisis actual. 


\section{Interpretación discontinuista y continuista del pensamiento de Keynes}

Según una interpretación muy común, y conocida como interpretación discontinuista del pensamiento keynesiano, los trabajos de Keynes publicados antes de la Teoría General pertenecen, o cuanto menos, están alineados con la tradición neoclásicomarshalliana, tanto por sus contenidos, como por las categorías económicas utilizadas (cfr. Patinkin 1956 y Blaug 1968). Solo en su Teoría General, en efecto, Keynes consiguió elaborar una teoría en grado de revolucionar radicalmente el saber económico a partir de sus fundamentos, negando la validez de la ley de los mercados de Say, en favor de una teoría que identifica la causa de la oferta agregada en la demanda agregada. Según esta interpretación, la conclusión analítica más extrema de Keynes está en su demostración de la existencia de equilibrio económico en condiciones de desempleo, que lo llevó a rechazar las recetas de posición liberal y a sostener la necesidad de ayudar el lado de la demanda mediante políticas fiscales expansivas. Este tipo de lectura de la contribución científica de Keynes ha sido la base de referencia para una campaña teórica y cultural de gran envergadura que respalda la idea que el modelo de la Teoría General representa nada más que un caso muy especial del modelo del equilibrio económico general. En la teoría de síntesis neoclásica de Hicks y Hansen, en efecto, el modelo de la Teoría General es considerado como el caso especial de la crisis, a propósito de la "trampa de liquidez"; así como la literatura posterior enseña que el mismo modelo IS-LM es a su vez un caso especial del modelo de demanda-oferta agregada; y que este modelo es todavía un caso especial del modelo de oferta y demanda agregada con expectativas (el caso de expectativas adaptativas).

La idea de la discontinuidad en el pensamiento de Keynes ha ido desarrollándose no sólo en el ámbito del pensamiento neoclásico, pero también en el de la heterodoxia, tanto por parte de los neo-ricardianos como por parte de unos post-keynesianos. En su reconstrucción de la evolución del pensamiento de Keynes, por ejemplo, Pasinetti (1999, p.7), refiriéndose a lo que escribe el mismo Keynes en el prefacio a la edición japonesa de su Tratado de la Moneda, propone una interpretación del cambio en el pensamiento de Keynes, basado en la idea que, dado los acontecimientos efectivos de las economías industriales de su época y los instrumentos analíticos que se desarrollaron para poderlos explicar, se convenció el mismo que los contenidos del Tratado de la Moneda sufrían de fundamentos incorrectos.

Poco después de la publicación del Tratado, principalmente, pero no sólo, como resultado de una combinación de acontecimientos efectivos (tales como la aparición, en todas las economías industriales, del desempleo total) y de innovaciones teóricas tales como la aparición de una serie de nuevas herramientas analíticas (por ejemplo, el multiplicador y el principio de demanda efectiva), Keynes debe haber concebido repentinamente que todas las discusiones que había mantenido con los economistas jóvenes del Circulo y con sus colegas, en el gobierno y en la universidad, adolecían de haberse planteado con fundamentos incorrectos. Su elaboración, [en efecto], se 
había basado en una versión marshalliana del paradigma del "intercambio". (trad. es., ibid., p. 10).

Es decir que según Pasinetti la transición del Tratado de la Moneda a la Teoría General debe ser leída como la transición del paradigma neoclásico del "intercambio" al paradigma de la escuela clásica inglesa de la "producción" - en la línea que va de Smith a Malthus y Ricardo (véase Pasinetti 1991). Por esta razón Pasinetti (véase también Boitani 1991 y Enria 1991) mira al pensamiento contenido en la Teoría General en términos de una verdadera revolución científica a la Kuhn, capaz de producir un cambio memorable y significativo de paradigma económico1.

El Tratado de la Moneda se proyectó como conclusión de un modelo teórico heredado de la tradición, mientras que la Teoría General fue pensada para ser el primer paso en la construcción de un nuevo paradigma. (Pasinetti 1991, p.50).

Pasinetti (1974), además, acentúa también la compatibilidad del análisis de Keynes de la Teoría General con la tradición clásico-Ricardiana, tanto en plano metodológico como en el del análisis económico puro (véase Pacella-Tortorella Esposito 2012). En el plano metodológico, en efecto, compatiblemente con el análisis de Ricardo, Keynes se centra en los macro agentes y las variables macroeconómicas, rechazando el individualismo metodológico. En el plano puramente analítico, la compatibilidad del pensamiento de Keynes con la tradición clásico-Ricardiana se puede encontrar en particular en la teoría del capital, donde, como señala Pasinetti, la teoría de Keynes, no sólo se presenta con un enfoque muy crítico a la teoría marginalista del capital, sino además es compatible con la hipótesis del rendimiento decreciente de Ricardo (véase también Garegnani 1979 y Dobb 1973). En este sentido la posición de los economistas neo-ricardianos con referencia a la interpretación discontinuista del pensamiento de Keynes como caso especial del modelo del equilibrio económico general, anteriormente analizada, es muy negativa. Ellos, en efecto, suelen considerarla simplemente engañosa, presentándose, a sus ojos, nada más que una relectura forzosa del análisis de Keynes, conducida con las herramientas analíticas marginalistas. La versión Hicksiana del pensamiento de Keynes, por ejemplo, representa según Pasinetti un simple intento para disminuir las innovaciones teóricas de Keynes para presentarlas como pertenecientes a los planteamientos analíticos tradicionales (Pasinetti, 1974, cap. II, par. 7, p. 64). Lunghini (1988) también considera el esquema Hicksiano de la síntesis neoclásica como algo que simplemente tenía el objetivo de simplificar la Teoría General, depurándola de las expectativas de los

\footnotetext{
${ }^{1}$ La interpretación revolucionaria del pensamiento keynesiano de Pasinetti encuentra su aplicación más clara en su modelo de oferta multi sectorial. Este modelo, en efecto, está establecido en un esquema keynesiano de Teoría General, donde el mercado generalmente trabaja con equilibrios de bajo empleo, con la posibilidad de conseguir el pleno empleo solo a través del crecimiento de la demanda global (Pasinetti 1990, cap. 2, par. 3, pp.39-40).
} 
capitalistas y de sus causas históricas (Lunghini, 1988, p.73, par.1.5), eliminando por esa vía el espacio para cualquier análisis dinámico (Ibid., p.85).

La interpretación discontinuista del pensamiento de Keynes pertenece también al planteamiento teórico de los post keynesianos que leen la producción científica del economista de Cambridge, prestando más atención a los aspectos de vanguardia del análisis contenido en la Teoría General, que a la visión preanalítica que caracteriza toda la obra de Keynes. Partiendo de la tesis que una escuela de pensamiento se reconoce por su liderazgo intelectual de referencia, su manifiesto de estudios y su revista especializada, una primera definición de escuela post keynesiana ha sido elaborada alrededor de unos estudiosos que escriben de forma regular en el Journal of post Keynesian Economics, que adoptan como manifiesto de sus estudios la Teoría General de Keynes, usando de esta manera un enfoque analítico inspirado en los principios de la demanda efectiva y de la importante influencia en las decisiones económicas de la preferencia de la liquidez, y que se reconocen como investigadores europeos que se benefician de la escuela Inglesa de Cambridge, asociada a la obra de economistas como Geoff Harcourt, Richard Kahn, Nicholas Kaldor, Michael Kalecki, Joan Robinson, Luigi Lodovico Pasinetti y Piero Sraffa, o a la "americana", asociada a los nombres de Victoria Chick, Alfred Eichner, Jan Kregel, Hyman Minsky, Basil Moore, George Shackle, Sidney Weintraub, Paul Davidson (Holt, 1997). En base a esta definición, no obstante, quedarían fuera de la categoría del post keynesianismo todos que se dedican a estudios de teoría monetaria de la producción, porque a pesar que encuentran espacio en el Journal of Post Keynesian Economics, y también comparten la misma visión del mundo de los estudiosos antes nombrados, se diferencian de estos porque adoptan como su manifiesto privilegiado de estudios el Tratado de la Moneda de Keynes. Referente a este último aspecto, la tesis más acreditada es que, aunque si los estudiosos de teoría monetaria de la producción y los post keynesianos están animados del mismo objetivo de elaborar un modelo macroecónomico alternativo al neoclásico-walrasiano, no pertenecen a la misma escuela de pensamiento debido a sus "distintas fuentes de inspiración" (Fontana y Realfonzo, 2005, p. 6) y a la consiguiente manera distinta de definir la categoría económica de la moneda (cfr. Delaplace \& Nell, 1996; Rochon \& Rossi, 2003). Si es cierto, en efecto, que ambos grupos de estudiosos: a) rechazan el individualismo metodológico, en favor de "una teoría macroeconómica que sea capaz de explicar los comportamientos observables de los agentes económicos, según una relación causal inversa" (Rochon \& Rossi, 2003, p. XXXIV) que procede de la macroeconomía a la microeconomía; b) rechazan la visión de un sistema económico que trabaje en base al esquema del equilibrio económico general y simultáneo, apostando en cambio por un esquema de tipo secuencial; c) comparten la idea que el crédito bancario sea un elemento decisivo en el proceso productivo y que la 
oferta de moneda sea endógena 2 ; d) comparten la convicción que la tasa de interés sea una variable exógena "que el banco central puede mejor controlar que la oferta de moneda" (Ibid., p. XXXIV), como instrumento de política económica.

Al mismo tiempo, ya que la moneda en los escritos de teoría monetaria de la producción está considerada sobre todo en su forma de medio de pago (y entonces como una variable de flujo), mientras que en aquellos post keynesianos se considera sobre todo en términos de reserva de valor (y entonces como una variable stock), en sus trabajos se encuentran las siguientes diferencias teórico-analíticas: 1) mientras para los post keynesianos, la moneda, siendo un título con un elevado grado de liquidez, viene normalmente mantenida como cobertura contra los riesgos atados a la incertidumbre de los acontecimientos futuros, operando por esa manera como un puente entre el presente cierto y el futuro incierto, para los estudiosos de teoría monetaria de la producción, la misma moneda, siendo medio de pago, viene de norma utilizada para regular las transacciones económicas entre los macro agentes, presentándose así como algo que pertenece sobre todo al presente; 2) mientras que los post keynesianos equiparan la actividad de los bancos a aquella de cualquier otra empresa, tanto que normalmente cargan el dado mark-up decido por el banco central en sus operaciones y compiten también en el mercado de los títulos, para los estudiosos de teoría monetaria de la producción el papel de los bancos está limitado al de la financiación de las actividades productivas 3 ; 3) mientras que según el enfoque post keynesiano el carácter endógeno de la moneda está atado al hecho que la curva de oferta de moneda depende de la tasa de interés y del nivel del ingreso agregado, con inclinación horizontal (oferta de moneda que perfectamente se adapta a la demanda de moneda de las empresas) o positiva (oferta de moneda que parcialmente se adapta a la demanda de moneda de las empresas); siguiendo el enfoque de la teoría monetaria de la producción "[la concepción de] una curva de oferta de moneda [es rechazada]" (Delaplace \& Nell, 1996, p. 25), porque dicha oferta siempre deriva de la demanda de moneda expresada por los empresarios para financiar sus actividades de producción (véase Rochon y Rossi, 2003, pp. XX-LVI; Graziani, 1994, pp. 13-31; Graziani, 2003, pp. 1-32).

Una definición de escuela post-keynesiana sin duda más inclusiva de la examinada poco antes se encuentra en la introducción del libro de John King sobre la historia del pensamiento post keynesiano, donde se consideran post keynesianos todos los que se reconocen y se definen como tales (King, 2002, p. 5). De hecho, pero, esta definición lleva un criticismo muy importante, detectado por parte de Davidson en las páginas

\footnotetext{
${ }^{2}$ Se supone que los bancos creen nueva moneda ex nihilo para favorecer las exigencias de liquidez de los empresarios, destinadas a la financiación de sus actividades productivas (es por eso que la moneda endógena es también definida credit-led y/o demand-driven).

${ }^{3}$ Así, mientras que según la visión post keynesiana los bancos están sujetos a los riesgos atados al mercado de los títulos, para aquella de la teoría monetaria de la producción los riesgos de los bancos dependen sobre todos de las posibles insolvencias de los empresarios.
} 
del Journal of Post Keynesian Economics (Davidson 2003-4). Un criterio tan subjetivo como el de King es muy problemático, por ejemplo, cuando hay que enfrentarse con casos como el de Paul Samuelson, que "se ha definido "post keynesiano" en muchas ediciones de su famoso libro de texto, [sin embargo afirma] en sus Fundamentos de Análisis Económico [...] que los estudios de la economía requieren unos axiomas clásicos, rechazados en La Teoría General de Keynes» (Davidson 2003-4, p. 246), como los de la neutralidad de la moneda, de la sustituibilidad de la moneda con bienes fácilmente disponibles y de la ergodicity, por lo cual el futuro implica riesgos siempre previsibles (Samuelson, 1968). Una tercera definición, también inclusiva, pero menos problemática de la de King, considera pertenecientes a la escuela post keynesiana todos los estudiosos que no sólo se reconocen y se definen como tales, ya que comparten las enseñanzas de Keynes, sino que comparten al mismo tiempo la finalidad de definir un paradigma teórico alternativo al mainstream, rechazando tanto los fundamentos teóricos del modelo neoclásico-walrasiano como los de la versión keynesiana del modelo de la síntesis neoclásica (véase Harcourt, 1985, p. 125 y 1988, p. 924; Eichner, 1985, p. 51; Sawyer, 1988, p. 1; Hamouda y Harcourt, 1988, p. 2; Hodgson, 1989, p. 96; Arestis, 1990, p. 222; Dow, 1992, p. 176).

A diferencia del primer enfoque considerado, los dos últimos, incluyendo en el contexto de la escuela post-keynesiana a estudiosos muy heterogéneos, sugieren estudiar el pensamiento post-keynesiasmo adoptando una lógica pre-analítica schumpeteriana (véase Schumpeter, 1990, vol. I, pp- 15-16; Lunghini, 1990, pag. XXVII XXXII; Costabile, 1986, pp. 147-168), donde la visión del mundo asume una función prioritaria con respecto al contenido analítico del modelo. Por lo tanto, centrándose en particular en el último enfoque, ya que, como se ha visto, gracias a este se evita el riesgo de incluir entre los economistas keynesianos a quien en realidad no lo es, se puede tratar de clasificar como post-keynesianos aquellos que siguen las enseñanzas de Keynes y que comparten una visión pre-analítica de la economía capitalista, supuesta como una economía monetaria y no cooperativa - a diferencia de la hipótesis neoclásica que, al contrario, la considera como una economía de trueque indirecto, en la que la moneda sirve sólo como bien de intercambio, de acuerdo con la teoría de la neutralidad de la moneda (ver Realfonzo, 1998; Figuera, 2001; Fontana y Realfonzo, 2005). En particular, la hipótesis de la naturaleza no cooperativa (Robertson 1926) del capitalismo describe una economía en la que trabajan dos distintos macroagentes, con finalidades y vínculos divergentes: los empresarios, que, siendo propietarios de los bienes de producción, de hecho deciden qué y cuánto producir, según el principio de la demanda esperada y efectiva, definiendo así los planes de producción, y entonces el nivel de las inversiones; y los trabajadores, que, al contrario, no siendo dueños de los bienes de producción que necesitan para trabajar, sólo pueden esperar encontrar trabajo en las empresas, a través de percibir a cambio de sus servicios laborales un ingreso salarial, a repartir entre los consumos y el ahorro, con el objetivo de mantener por lo menos constante el nivel de sus actividades de consumo en el tiempo. En un esquema como éste, a donde las elecciones de inversión y de ahorro pertenecen a dos 
sujetos tan distintos por intereses y vínculos, se verifica que: a) el nivel del ahorro y el de las inversiones no necesariamente tienen que igualarse, como ocurre en los esquemas neoclásicos-walrasianos; b) por lo tanto, se crea incertidumbre en el sistema económico alrededor de su curso futuro; c) en presencia de esta incertidumbre sistémica, el individualismo metodológico de tipo neoclásico, conforme los agentes económicos actúan respecto al axioma de la racionalidad y bajo condición de perfecta información, pierde significado. De aquí, ya que, como el mismo Keynes acuerda, en una economía no cooperativa la producción se realiza según el esquema de Marx DM-D' ${ }_{4}$ (Keynes 1979), es posible afirmar que una de sus principales características es que de hecho funciona como una economía monetaria5, porque, dado el papel determinante que juega la moneda en el proceso de producción, se presenta como un sistema donde: "a) para entender su funcionamiento real [...] es necesario analizar el papel que la moneda desenvuelve en la fase de la producción y no en aquella del intercambio; b) los distintos momentos de la vida económica (producción, distribución e intercambio) y las elecciones de los agentes - [bancos, empresarios y trabajadores] - siguen uno a otro tanto en el tiempo histórico como en el lógico; c) la moneda tiene naturaleza crediticia" (Zazzaro, 1995, p. 117); d) el papel de los bancos es el de insertar nueva moneda en el sistema económico, creándola antes de todo para favorecer la financiación de las actividades de los empresarios. En consecuencia, según el criterio pre-analítico un estudioso puede considerarse post-keynesiano si comparte: 1) el rechazo del individualismo metodológico; 2) la adopción del análisis secuencial para estudiar el funcionamiento del sistema económico; 3) la teoría de la naturaleza endógena de la moneda; 4) el papel fundamental de la demanda efectiva; 5) el papel de la incertidumbre; 6) la teoría de la distribución de la renta de tipo no-marginalista; y 7) la separación del mercado de la moneda del financiero.

Dado que la definición de escuela post-keynesiana según la lógica pre-analítica schumpeteriana que acabamos de analizar es la que los teóricos del enfoque continuista del pensamiento de Keynes normalmente adoptan, en los próximos párrafos, partiremos de un estudio de los problemas empíricos que Keynes intentó sobrepasar en sus dos obras más representativas - el Tratado de la moneda y la Teoría General iremos en busca de los imperativos ontológicos y metodológicos que las caracterizan,

\footnotetext{
${ }^{4}$ A donde se asume que la función de la moneda es aquella de ser empleada en el sector real de la economía para producir bienes que vendidos en el mercado sean capaz de devolver una cantidad más grande de moneda.

${ }_{5}$ Para citar a Keynes: "La distinción entre la economía cooperativa y una economía empresarial se vincula en parte a una observación hecha por Karl Marx, [...] [según que] en el mundo real, la naturaleza de la producción no es [...] un caso de M-D-M ', o sea el intercambio de bienes (o de trabajo) con una moneda con el fin de obtener otros bienes (o otro trabajo); [porque] esto puede ser el punto de vista del consumidor aislado, pero no [aquel] del mundo de los negocios, que pertenece, por el contrario, al caso [del esquema] D-M-D ' y que consiste en vender la moneda a cambio de bienes (o de trabajo) con el fin de obtener una mayor cantidad de moneda"(Keynes 1979, p. 81).
} 
para individuar los fundamentos teóricos de dicho enfoque continuista que queremos utilizar en este trabajo para explicar las causas de la crisis económica actual.

\section{Los problemas empíricos y los imperativos ontológicos y metodológicos de Keynes}

Para definir los problemas empíricos que Keynes intentaba solucionar, es posible iniciar nuestros razonamientos a partir de las siguientes palabras de Patinkin que, con gran lucidez, explican las diferencias fundamentales existentes entre el Tratado de la moneda y la Teoría general.

"El Tratado de la moneda se propone la finalidad de presentar una teoría formal y rigurosa de la moneda, que sea capaz de afrontar en detalle los aspectos tan estáticos como dinámicos del problema. [...] "La teoría monetaria" del Tratado busca sobre todo explicar los mecanismos que subyacen a la determinación del nivel de los precios. [Pero esto no significa] que el Tratado ignorase las cuestiones relativas a la producción. Su propósito primario, al contrario, era el de explicar las fluctuaciones cíclicas de la producción y por tanto de la ocupación; [tema este afrontado, pero], no de manera directa, si no como efecto del cambio de los precios. [...] Lo que distingue la Teoría general del Tratado de la moneda, [pero], no concierne tanto a su manera de estudiar el tema de los cambios de la producción de modo más directo y preciso, en cuanto al papel crucial que se le atribuye a estos cambios como fuerza de equilibrio entre la demanda y la oferta agregada, o sea entre el ahorro y las inversiones" (Patinkin 1975, pp. 254-256).

Dos cosas importantes surgen de las palabras de Patinkin: que el dominio de investigación científica de Keynes concierne a la macroeconomía y que los problemas empíricos a que Keynes intentaba dar solución son anómalos, en el sentido laudaniano del término (Laudan 1979), siendo que él se concentró en los temas del carácter cíclico de las economías capitalistas y del origen de las crisis económicas, sobre el cual el paradigma neoclásico no fue capaz de suministrar una explicación satisfactoria.

En particular, Keynes en el Tratado de la moneda se dedicó sobre todo al tema de "las inestabilidades de las economías de mercado" (Fontana y Realfonzo, 2005, p.7), adoptando un esquema teórico que estudia la economía capitalista como un sistema no cooperativo, caracterizado de la existencia de una moneda cuya naturaleza y cuya funciones difieren de aquellas definidas en el marco de la teoría neoclásica tradicional.

Partiendo de la naturaleza de la moneda, en el Tratado, Keynes niega la hipótesis de que la moneda es una mercancía, sustituyéndola con la de la moneda signo, según que la moneda está considerada en términos de unidad de cuenta6. Para Keynes, en efecto, en un sistema económico adelantado, donde las relaciones comerciales se

\footnotetext{
${ }^{6}$ Esto implica que por Keynes la moneda tiene naturaleza simplemente simbólica: es un puro signo.
} 
concretan a través de boletines de precios y deudas, las características que la moneda empleada en concreto para regular las obligaciones contractuales tiene que tener, dependen propiamente de las relaciones que ella mantiene con la moneda de cuenta, porque las deudas y los precios que debe liquidar están definidos ya en principio en términos de moneda de cuenta; y no de moneda circulante, entendida sencillamente como la expresión material de la moneda de cuenta (Cfr. Hawtrey 1919; Robertson 1935 y 1993). Citando a Keynes:

"La teoría de la moneda toma como punto inicial la concepción de moneda de cuenta, [cuyo origen está en] las deudas, que son contratos de pago diferido, y [en los boletines de precios], que son las ofertas para contratos de venta o de compra. [...] La moneda misma, es decir la entidad que resuelve los contratos de deuda y de precio y en cuya forma se tiene una disponibilidad general de poder de compra, conlleva su propio carácter derivado de sus relaciones con la moneda de cuenta, porque las deudas y los precios deben ser antes de todo expresados en términos de esta última. [...] Podemos [entonces] aclarar la distinción entre moneda y moneda de cuenta diciendo que la moneda de cuenta es la palabra o el título y la moneda es lo que corresponde a la palabra" (Keynes, 1932, pp. 3-4).

La moneda de cuenta, no obstante, dado que nace de las deudas y de los boletines de precios, necesita como su presupuesto necesario la intervención de un agente super partes, como el del Estado, capaz de actuar al mismo tiempo: como garante para el cumplimiento regular de las obligaciones contractuales y como decisor de su correspondencia real con la moneda materialmente utilizada en las transacciones, que Keynes define con el término moneda propiamente dicha. Esta, pero, en los sistemas económicos adelantados no es la única forma de moneda que circula; generalmente, en efecto, está acompañada de otras dos formas de moneda, es decir de la moneda bancaria $_{7}$ y de aquella representativa ${ }_{8}$, con lo que la circulación de la moneda resulta de hecho estrechamente atada a la confianza y/o a la autoridad de quién la empuja en el sistema económico (cfr. Furness 1910, pp. 94-106)9, más que a un supuesto valor

\footnotetext{
${ }^{7}$ Citando a Keynes, la moneda bancaria se puede definir como el "reconocimiento de una deuda privada, expresada en moneda de cuenta [...] que se suele transferir de una persona a otra, como una alternativa a la moneda propiamente dicha, con el fin de regularizar unas operaciones" (Keynes 1932, p. 7).

${ }^{8}$ Definida por Keynes como "una deuda del Estado que, [haciéndose fuerza] de su prerrogativa cartalista, [declara] que la deuda misma tiene el poder liberador legal" (Keynes 1932, p. 8).

${ }^{9}$ En su Island of Stone Money, Furness enseña cómo la circulación monetaria está, de hecho, vinculada a la confianza y/o a la autoridad de quien empuja el circulante en la economía, a través del caso de la circulación monetaria de la isla de la UAP (Carolina), donde los habitantes utilizaban como moneda unas grandes piedras circulares, llamados fei, porque estaban convencidos que los marineros que las habían traído de una isla lejana que tenían un elevado valor. El poder adquisitivo de los habitantes de la isla de la UAP (Carolina) se relacionaba con la importancia del ejemplar del fei del que se jactaban derechos de propiedad, incluso desvinculados de su posesión, así que una familia dueña de un importante ejemplar de
} 
intrínseco que le confiere el poder de ser intercambiada con las mercancías vendidas en el mercado, como sostenía la teoría neoclásica.

Pasando a las funciones de la moneda, hay que remarcar como al lado de su función reguladora de las obligaciones contractuales, en el Tratado de la moneda Keynes le reconoce otro papel importante, incluso decisivo, en el proceso de producción de los bienes; es decir el que se refiere a su utilización para la financiación de la actividad de producción de las empresas. Estas, en efecto, siendo que para empezar a producir necesitan de una cierta cantidad de moneda para adelantar el pago de los salarios a los trabajadores, las empresas piden a los bancos que, para este fin, previamente generan nueva moneda a través de oportunas escrituras contables $\mathrm{y}$, entonces, la ceden a los empresarios para satisfacer sus exigencias.

A partir de aquí, en contra de lo dispuesto en el modelo neoclásico, tenemos que en el Tratado de Keynes, la oferta de moneda no es exógena sino endógena, porque es impulsada por la demanda de moneda definida por las empresas para financiar sus actividades. Razonando a partir de estos asuntos y dada la definición de Keynes de moneda bancaria, entendida como una deuda privada con poder liberatorio legal (véase nota n. 11), es posible afirmar que la creación de moneda bancaria corresponde a la creación "de derechos de recibir moneda [del mismo banco]" (Keynes 1932, p. 32), operación ésta que se puede concretar a través de tres modalidades distintas: 1) a favor de los depositantes que, trayendo moneda contante al banco, ganan el derecho de recibir moneda del banco personalmente o de transferir moneda a terceros a través de operaciones de giro; 2) a través de la adquisición por parte del mismo banco de activos frente a una apertura temporal de crédito a su mismo nombre; 3 ) a través de una apertura de crédito por parte del banco a su mismo nombre en favor de un tercer prestatario, detrás de la promesa de este último de devolver la suma recibida en préstamo. Por esta vía, entonces, los bancos "reciben de forma continua efectivo y [siempre] de forma continua [lo pagan]" (Keynes, 1932, p. 33), haciendo que esta función de compensación del banquero resulte indispensable para evitar la excesiva reducción de las reservas, así que cuando la moneda en circulación aumente, también las reservas de los bancos participantes crecen, situándoles así en las condiciones de estar más disponibles para dar crédito a los empresarios en condiciones más ventajosas (Keynes, 1932, p. 381).

En cuanto a la introducción de moneda nueva en el sistema económico por parte de los bancos, tenemos que de un lado, se consigue estimular las inversiones en actividad productiva; $y$, al mismo tiempo, es causa también del curso cíclico del sistema económico, puesto que, si los costes de producción fuesen constantes, el poder de compra de la moneda nueva introducida en el sistema económico crecería

fei estaba considerada rica, incluido el caso que el ejemplar en cuestión se hubiese perdido por causas de fuerza mayor. 
cuando la cantidad total del ahorro excediese el coste de las inversiones y se reduciría en el caso contrario. Es así que el modelo keynesiano del Tratado de la moneda se presenta como un modelo donde el equilibrio representa la excepción y no la regla, porque, suponiendo una economía capitalista caracterizada por la presencia constante de los conflictos de intereses entre el grupo social de los empresarios y el de los trabajadores, no puede existir ninguna ley universal capaz de garantizar el equilibrio entre el valor de las inversiones y el de los ahorros en cada momento, siendo que el primero lo deciden los empresarios con la finalidad de conseguir beneficios, mientras que el segundo depende de las decisiones de los trabajadores referente a la repartición de sus renta entre los consumos y el ahorro. De aquí sigue que la continua alternancia "[de excesos y de defectos] del coste de las inversiones referente al volumen del ahorro y los [siguientes] altos y bajos del poder de compra de la moneda" (Keynes 1932, p. 403), definido por Keynes como ciclos del crédito, inevitablemente generan, a sus veces, los ciclos económicos. Si, en efecto, la expansión de la actividad de las empresas está unido a la concesión de créditos por parte de los bancos, una contracción del crédito, debida a una reducción del poder de compra de la moneda, provocará un descenso de la misma actividad de las empresas y viceversa.

De cuánto lo dicho es posible concluir que uno de los aspectos fundamentales que Keynes quería recalcar en el Tratado es lo de la importancia del papel del sistema bancario en una economía monetaria como la capitalista. Conforme a lo que hemos visto, en efecto, ya que el sistema económico se caracteriza por su misma naturaleza por la constante existencia de ciclos, el papel de los bancos en dicho sistema resulta indispensable, siendo estos los únicos, en caso de orientación bajista, que pueden volver a levantar los destinos del sistema económico a través de la introducción de nueva moneda en el sistema económico.

"Muchas razones [...] sí hacen que el volumen de las inversiones sufra fluctuaciones bastante amplias. El desarrollo de un boom de las inversiones no significa por cierto que los empresarios que lo inician han deliberadamente decidido que la gente tenga que ahorrar una cuota de la propia renta más grande que antes. [Tampocoi vale lo contrario]. Solo el sistema bancario tiene la posibilidad de ejercitar una previsión inteligente al efecto de igualar el ahorro y las inversiones; son en efecto las facilidades consentidas de los bancos que constituyen el factor marginal capaz que haya que determinar la medida precisa en que los empresarios podrán dar desenvolvimiento a sus empresas" (Keynes 1932, pp 405-406).

El último tema que hemos tratado, o sea el problema de la determinación del nivel de la producción y de la ocupación, ha sido ulteriormente objeto de estudio por parte de Keynes en la Teoría general (1936), a donde en el prefacio el economista de Cambridge explica las diferencias sustanciales entre los contenidos teóricos de su nuevo trabajo y el Tratado de la moneda, utilizando las siguientes palabras:

"La relación que existe entre este libro y mi Treatise on Money [...] es que éste representa una evolución natural de la línea de pensamiento que ya persigo desde hace muchos años. Cuando inicié a escribir mi Treatise on Money me estaba aún 
moviendo en el trayectoria de la línea de pensamiento tradicional. [...] Cuando lo ultimé, había hecho unos progresos en la dirección de empujar la teoría monetaria a volverse en una teoría de la producción en su complejo. [...] Pero mis así llamadas "ecuaciones fundamentales" representaban un cuadro instantáneo definido referente a la hipótesis de un dado nivel de producción. [...] El desarrollo de un análisis dinámica [...] se quedó [así] incompleto y extremadamente confundido. Este libro es, entonces, una evolución del otro, ya que se ocupa ante todo del estudio de las fuerzas que determinan variaciones en la escala de producción y en la ocupación en su complejo [... enseñando] que una economía monetaria es esencialmente una economía en la que, variaciones en las expectativas del futuro están capaz de influenciar el nivel de la ocupación y no sólo su simple tendencia" (Keynes 1936, pp. VI-VII).

Los académicos que se han enfrentado a la obra de Keynes, pasando por esta declaración de intenciones sobre el contenido y los objetivos de la Teoría general con respecto a aquellos del Tratado de la moneda, se han dividido en dos líneas distintas de interpretación en cuanto a las relaciones entre los dos textos considerados: uno de tipo discontinuista, según que el Keynes del Tratado de la moneda, todavía fuertemente anclado a la tradición neoclásica de Marshall, con la publicación de la Teoría general dejó el paso a un nuevo Keynes, promotor de una visión revolucionaria de la teoría económica, basada en un verdadero vuelco de la ley de los mercados de Say; y uno de tipo continuista, según que existen varias razones teóricas e históricas para creer que los contenidos de la Teoría general deben ser leídos teniendo en cuenta la continuidad de pensamiento que hay entre ellos y los de las trabajos publicados antes y después. Según los académicos del enfoque continuista, en particular, es posible suponer que, Keynes, animado del objetivo de elaborar una estructura teórica alternativa a la de la tradición neoclásica, capaz de explicar la economía capitalista como una economía monetaria y no cooperativa, en el paso del Tratado de la moneda a la Teoría general, una vez explicado el funcionamiento de los ciclos del crédito y de aquellos económicos, en un contexto de moneda endógena, haya sentido la exigencia de desplazar su atención al lado de la demanda de la moneda, siendo consciente que las crisis no dependen sólo de los eventuales comportamientos poco complacientes de los bancos en conceder crédito a los empresarios; sino también de la tendencia de la gente a atesorar la moneda para hacer frente a las incertidumbres relativas al futuro (véase Graziani; Forges Davanzati y Realfonzo). En la Teoría general, en efecto, las conclusiones primarias de Keynes referente al origen de las crisis económicas se apoyan en la hipótesis de que el sistema económico, conforme su misma naturaleza, se caracteriza por la incertidumbre y sobre la tesis de que la moneda no sirve sólo como unidad de cuenta en las transacciones comerciales, actúa también como reserva de valor debido propiamente a la incertidumbre sistémica que marca el funcionamiento de la economía capitalista. Citando a Keynes, en efecto: "[el] deseo [del hombre] de mantener moneda bajo forma de reserva de valor es un barómetro de [su] grado de confianza [referente a sus] cálculos y a sus convenciones concernientes el future" (Keynes, 1937, p. 216). 
De aquí, ya que la incertidumbre no consiente a los operadores económicos prever con precisión el futuro, estos están animados a tomar sus propias decisiones, de inversión y de consumo, de acuerdo a sus grado de confianza en el futuro del sistema económico, o sea de acuerdo a las propias expectativas10. En caso de expectativas pesimistas, por ejemplo, las familias quieren aumentar las propias reservas líquidas para hacer frente a los acontecimientos futuros (pérdida de confianza en el sistema económico), con consiguiente aumento de la tasa de interés ${ }_{11}$, mientras que los empresarios tratarán de contraer el propio gasto en inversiones; y viceversa. De aquí, en el sector monetario se producirá una contracción de la velocidad de circulación de la moneda, mientras que en el real una bajada de la demanda agregada, con consiguiente reducción de la oferta agregada, contracción de la producción y entonces de la ocupación. Basándose en estas conclusiones, entonces surge el enfoque interpretativo continuista de la obra de Keynes, concluyendo el economista de Cambridge en el Tratado de la moneda y en la Teoría general mediante soluciones a dos distintos problemas empíricos anómalos que el paradigma neoclásico no fue capaz de explicar, adoptando en las dos obras la visión pre analítica común de la naturaleza no cooperativa y monetaria, basada en el trabajo salarial, de la economía capitalista. El, en efecto, mientras que en el Tratado explica el carácter cíclico de la economía capitalista como fruto de los ciclos del crédito, debidos a los desequilibrios continuos que se registran entre el nivel de las inversiones y el del ahorro, en la Teoría general demuestra como las crisis económicas dependen de la tendencia de los operadores a atesorar la moneda para protegerse contra las incertidumbres atadas al futuro de la economía, suministrando así una interpretación de la crisis como un caso especial del funcionamiento cíclico de la economía capitalista, debido al fenómeno de la acumulación de la moneda en forma líquida en condiciones de incertidumbre sistémica, cuando colapsa la confianza de los operadores respecto a los acontecimientos futuros del sistema económico (v. Forges Davanzati Realfonzo y Seccareccia 2004).

"Examinando [sus] dos trabajos, [en efecto], hay la clara impresión que, con algunas variaciones inevitables, la Teoría general puede ser incorporada en el Tratado de la moneda, a lo mejor, [...] como fase particular del ciclo del crédito. [...] Para enseñar el ciclo del crédito, el Tratado de la moneda adopta [...] un proceso lógico que cubre un ciclo completo. De otra manera, en la Teoría general, el representa un intervalo del tiempo lógico a donde el nivel de la inversión, el stock de capital y el estado de las expectativas de largo plazo son todos dados. En este caso se puede concebir la dimensión espacio temporal del ciclo del crédito de Keynes del Tratado de la moneda

\footnotetext{
${ }^{10}$ Cuya naturaleza nace en factores psicológicos y subjetivos de los operadores mismos (vea Keynes 1921).

${ }^{11}$ Que en este razonamiento toma la forma de una especie de cobertura contra los riesgos que hay que conceder a las familias para convencerlas a reducir sus defensas líquidas en favor de la compra de títulos.
} 
simplemente como una larga secuencia de muchos períodos de corto plazo [a la Marshall] de la Teoría general" (trad. es. Seccareccia 2004, p. 302).

Una vez que se han individuado los problemas empíricos a que Keynes se dedicaba, se puede proceder a investigar sobre los imperativos ontológicos y metodológicos por parte del economista de Cambridge, según los problemas empíricos que intentaba solucionar.

Basándonos en lo que hemos dicho poco antes, es posible afirmar que el primer imperativo ontológico adoptado por parte de Keynes en sus obras es el de considerar la naturaleza de la moneda en términos de unidad de cuenta; hipótesis esta de primera importancia ya que permite estudiar la economía capitalista como una economía monetaria, donde la moneda asume un rol fundamental en el proceso de producción de los bienes, sobrepasando por esta manera la visión tradicional del sistema capitalista, fundado en la hipótesis de la naturaleza mercantil de la moneda.

Otro imperativo ontológico reconducible a la obra de Keynes concierne a la imagen conflictiva de las economías capitalistas, caracterizada por la co-presencia de macro agentes, cuyas acciones económicamente relevantes están condicionadas por objetivos y vínculos divergentes. También este imperativo es de importancia nada despreciable, porque lleva unas importantes consecuencias: 1) que el equilibrio macroeconómico neoclásico, según que el nivel de las inversiones debe siempre igualarse al del ahorro no necesariamente debe verificarse; 2) que el sistema económico, en ausencia de una condición cualquiera que garantice el equilibrio entre inversiones y ahorro, resulta impregnado de incertidumbre sistémica12;3) que el distinto acceso de los macro agentes a la moneda tiene un impacto decisivo en la distribución del producto interno bruto.

El tercer elemento ontológico concierne a la oferta de moneda endógena, cuya importancia consiste en el hecho que ella sustenta el funcionamiento de los ciclos del crédito, que Keynes utiliza, como se ha visto, para explicar el carácter cíclico de la economía capitalista. Un aumento de la oferta de moneda por parte del banco central, en efecto, genera un aumento de las reservas de los bancos participantes, permite a estos últimos poder prestar moneda en condiciones más ventajosas a los empresarios que la han pedido para financiar sus actividades de producción; y viceversa.

El cuarto imperativo ontológico atañe a la hipótesis keynesiana de la existencia de una dada incertidumbre sistémica en la economía capitalista, capaz de condicionar su funcionamiento regular; aunque si se habla explícitamente de incertidumbre sólo en la

\footnotetext{
${ }^{12}$ En la lógica post-keynesiana la incertidumbre depende del hecho que los operadores económicos toman sus decisiones económicamente relevantes en el presente, actuando según sus propios conocimientos limitados a los hechos contingentes e ignorando lo que sucederá o podrá suceder en el futuro, siendo conscientes de la influencia irreversible que los eventos económicos futuros, dependientes del tiempo histórico en lo que se verifican, pueden producir a cargo de los resultados de las elecciones económicamente relevantes ya tomadas.
} 
GT, y no en el TM, donde se alude a la incertidumbre sólo en manera indirecta. En el Tratado de la moneda, en efecto, siempre con referencia al problema de los ciclos del crédito, cuando se explica que la conducta bajista de los empresarios no acompañada de una adecuada introducción de nueva moneda en el sistema por parte de los bancos13 produce recesión, de hecho se utiliza el concepto de precio de los bienes de capital (tasa natural), definido en el capítulo de las ecuaciones fundamentales, como expresión de las expectativas de los empresarios referente a la futura tasa de rendimiento de las inversiones.

El quinto imperativo ontológico concierne al importante papel de la demanda efectiva en el sistema económico. En las obras de Keynes viene completamente volcado el orden jerárquico entre el lado de la demanda y el de la oferta. Para el economista de Cambridge, entonces, no es la oferta a producir la demanda, sino más bien vale lo contrario; de hecho, una contracción de la demanda, debida a una reducción o de los consumos de las familias y/o de las inversiones por parte de los empresarios, provoca una bajada inevitable de la oferta, con consiguiente contracción de la producción y de la ocupación.

El último imperativo ontológico, se refiere al papel de la demanda de moneda para propósitos previsores como causa de las crisis económicas. En la Teoría general, por ejemplo, Keynes explica que cuando la tasa de interés, percibida de los ahorrantes como seguro contra los riesgos de mercado, alcanza niveles demasiado bajos, la demanda de moneda para propósitos previsores aumenta, implicando un aumento de la cantidad de moneda retenida en forma líquida como reserva de valor para neutralizar los posibles acontecimientos futuros negativos inesperados, con consiguiente sustracción de moneda del sistema, y entonces bajada de las inversiones por parte de los empresarios, contracción de la demanda efectiva, de la oferta, de la producción y de la ocupación.

Basándose en lo que hemos analizado, surge como para Keynes las crisis económicas dependen de la incertidumbre sistémica que caracteriza las economías avanzadas; donde, en sus esquemas, esta misma asume simultáneamente tanto el papel de imperativo ontológico como el de regla metodológica. Keynes, en efecto, criticaba el método adoptado por los estudiosos de la escuela neoclásica, afirmando que ellos abstrayendo la incertidumbre de los acontecimientos futuros, acababan para sujetar el comportamiento de los agentes económicos a las leyes del mercado, cuando en la realidad ocurre lo contrario.

"Mi acusación a la teoría económica clásica es que esta se presenta como una técnica hermosa y elegante que intenta estudiar el presente, abstrayendo poco de los hechos que conocemos en torno al futuro" (Keynes 1936, p. 215).

En la realidad, en efecto, ya que los acontecimientos futuros son inciertos y no existe ningún cálculo capaz de identificar, ni siquiera de modo aproximado, la

\footnotetext{
${ }^{13}$ Para bajar la tasa de interés monetaria al nivel de la tasa natural de interés, reducido después del comportamiento bajista de los empresarios.
} 
probabilidad de lo que vaya a ocurrir, los operadores económicos que deben actuar en tales condiciones a menudo asumen unos comportamientos capaces de alterar el regular funcionamiento del sistema económico; como ocurre, por ejemplo, en dicho caso de la acumulación de moneda líquida, con su consecuente reducción en los niveles de la producción y de la ocupación. Referente a este propósito, Kregel afirma que el método utilizado por parte de Keynes se caracteriza por considerar la incertidumbre y las expectativas siempre presentes; y para evaluar sólo después de cada caso como actúan en el sistema económico eventuales cambios de las expectativas de los operadores económicos, pasando del corto plazo al largo plazo (Kregel, 1976, p. 211). Es así que el imperativo metodológico de Keynes se diferencia del neoclásico ya que a diferencia de este último, no fija ninguna hipótesis alrededor de las características del funcionamiento del mercado; por el contrario, considerando, como se ha dicho, un sistema económico caracterizado por la constante presencia de incertidumbre sistémica, los operadores económicos para decidir cómo actuar en el sistema económico, antes definen unas conjeturas sobre el curso futuro del sistema mismo y sólo después decidirán su línea de comportamiento que, como se ha visto, es capaz de afectar a los destinos del sistema económico mismo.

A estas alturas, después de haber investigado los problemas empíricos y los imperativos ontológicos y metodológicos de Keynes, en el próximo párrafo iremos a estudiar el planteamiento de una línea investigadora en particular de la tradición de investigación post-keynesiana; o sea, lo de la escuela italiana de la teoría monetaria de la producción, mejor conocida con el nombre de teoría del circuito monetario, a través del pensamiento de Augusto Graziani y de los principales estudiosos de su escuela, con la finalidad de utilizar este enfoque para comentar las causas de la reciente crisis económica explotada en el 2008.

\section{Deuda privada y crisis económica según la teoría del circuito monetario de la escuela italiana de Augusto Graziani}

La contribución teórica de Augusto Graziani basada en el esquema keynesiano de la Teoría monetaria de la producción, contenido en el Tratado de la moneda, se desarrolla gracias al uso de un enfoque metodológico de tipo histórico contextualizado, muy cercano a lo que se ha analizado en el párrafo precedente. Para estudiar el funcionamiento de una economía monetaria y las leyes que lo sustentan, Graziani propone la adopción de la categoría de la incertidumbre sistémica, cuyo origen es inherente a la naturaleza monetaria y no cooperativa del sistema económico. Argumentando en términos de naturaleza no cooperativa del sistema, la incertidumbre se crea porque en él operan tres distintos macro-agentes (bancos, empresas y trabajadores), cuyas decisiones económicamente relevantes están definidas en función de vínculos y objetivos divergentes: 1) los empresarios, que poseen los factores de la producción y tienen fácil acceso al crédito, definen sus propios planes de producción y por lo tanto el nivel de las inversiones, siguiendo la lógica del beneficio; 2) los bancos emiten nueva moneda para financiar las actividades de producción de las empresas; 3) los trabajadores se preocupan de decidir la forma más apropiada para asignar los ingresos percibidos en concepto de compensación por su trabajo entre el 
consumo presente y el consumo futuro, definiendo así el nivel de ahorro. Argumentando después en términos de la naturaleza monetaria del mismo sistema, la incertidumbre se convierte en un elemento esencial, ya que en su ausencia sucedería que los agentes económicos (sean éstos consumidores o empresas) estarían inclinados a pedir dinero sólo cuando realmente lo necesitasen, procurando que se destruyese al mismo tiempo que se creara, convirtiéndolo así en una variable no fácilmente observable; y esto se presenta como una verdadera paradoja en una economía monetaria (Graziani, 2003, pp. 11-12 y Graziani, 1996, p. 146).

En este sentido, Realfonzo (1998) argumenta que la distinción entre los estudiosos de la Teoría monetaria de la producción y los de la escuela neoclásica está en el rechazo por parte de los primeros del individualismo metodológico en favor de una teoría macroeconómica en la que se introduce la división en clases en el marco analítico, así que el comportamiento de los agentes económicos se estudia de acuerdo con una relación de causalidad inversa que va desde el análisis macroeconómico a aquel microeconómico (ver Zazzaro, 2000 y 2003).

«La tradición neoclásica se destaca por haber formulado modelos de una economía caracterizada por la ausencia de poder de clase y de conflicto de clase [...] la adopción del individualismo metodológico dio lugar a una nueva definición de agente económico [...]: en lugar de centrarse en un examen de la interacción de las clases sociales, los economistas [neoclásicos] centra[n] su atención en el análisis del comportamiento racional de los agentes considerados individualmente» (Realfonzo 1998, pp. 1-2).

Sin duda, una de las consecuencias más inmediatas que surgen cuando se considera un sistema económico caracterizado por la incertidumbre es el uso del dinero líquido, como una forma de defensa frente a posibles eventos adversos futuros (ver Forges Davanzati y Realfonzo, 2008; Forges Davanzati y Realfonzo, 2004). Los operadores del sistema, de hecho, no pudiendo de ninguna manera calcular, ni siquiera aproximadamente, la probabilidad con la que se producen determinados eventos, suelen utilizar la moneda como un escudo contra la incertidumbre; la moneda de esta manera asume una función de depósito de valor dentro del sistema económico y, como tal, tiene su utilidad directa. Sobre este tema, Graziani, citando Schlesinger (1914), recuerda como ya en los primeros años del siglo XX, se había clarificado con rigor científico que la moneda tiene una función de reserva de valor, utilizando las palabras siguientes:

"Supongamos que el déficit no puede ser cubierto por préstamos. Estos serán cubiertos sólo vendiendo las empresas $[\ldots]$ o alternativamente, por el tener reservas en efectivo cobradas en contra de estas contingencias [...] La pérdida individual de no ganar ningún interés sobre estas reservas puede considerarse como una recompensa contra el riesgo" (Graziani, 2003, p. 10).

Las aportaciones teóricas de Graziani a la Teoría monetaria de la producción estuvieron fuertemente influenciadas por su método. El argumenta, en efecto, que la Teoría monetaria de la producción se basa en cuatro características fundamentales (véase Graziani, 1977, 1984 y 1988; Bossone 2003): “El nivel de producción está determinado por las decisiones conjuntas de los bancos y de las empresas [...] y el 
nivel de actividad está determinado por las decisiones de apertura del circuito, y no por las condiciones de su cierre" (Graziani, 1988a, p 97.);

La cantidad de dinero en la economía está siempre definida por los acuerdos entre los bancos y las empresas con referencia al nivel de la producción, resultando, en este sentido, estrechamente endógena; con referencia al fruto de la actividad productiva de las empresas, lo que les interesa verdaderamente no es el producto en términos físicos, sino en términos monetarios, porque en su función objetivo hay un beneficio monetario y no la cantidad física de las mercancías producidas; las decisiones de producción de las empresas no dependen de los tipos de intereses vigentes en los mercados financieros, sino por los tipos de intereses que los bancos cobran por los préstamos.

En este contexto, existe una profunda diferencia entre las actitudes de los bancos y de los empresarios, que consiste en el hecho de que mientras los primeros emiten el dinero sin usarlo, las empresas necesitan utilizar el dinero para financiar sus actividades de producción, pero no pueden crearlo, para no encontrarse en una mera economía de trueque. Para que haya una economía monetaria de hecho, en efecto, la moneda tiene que ser emitida por un tercero, ajeno al intercambio, como el Estado (moneda fiduciaria) o el banco; así que el "pago [...] no deje ninguna relación entre el comprador y el vendedor [...] creándose, por el contrario, una relación de deuda entre el comprador y el tercer sujeto encargado de pagar [y] una relación de crédito entre el vendedor y este mismo sujeto tercero" (Ibid., p. 100).

Esto explica por qué las empresas, en una economía monetaria, para conseguir el dinero para producir deben necesariamente pedirlo a los bancos que, a tal efecto y de acuerdo con el nivel de la producción previamente decidido, crean nuevo dinero para prestarlo a los empresarios (ver Graziani, 1984, 1985 y 1987). Si se supone que el cierre del circuito de los flujos monetarios en equilibrio se logra siempre que las empresas sean capaces de ganar con la venta de sus productos los ingresos monetarios necesarios para extinguir las deudas contraídas con los bancos en la fase de abertura del circuito, se deduce que esto puede ocurrir sólo por casualidad, ya que depende del comportamiento de gasto de los operadores económicos. Citando Graziani, en efecto, se puede decir que:

«En términos muy generales, se puede [...] hablar de estado de equilibrio, cuando las empresas, habiendo ganado unos ingresos monetarios por lo menos iguales a los desembolso efectuados, pueden pagar sus deudas y cerrar las operaciones en equilibrio o en activo. [...] Lo que determina si el sistema económico se encuentra en equilibrio o fuera del equilibrio es sólo la propensión al gasto de los operadores. Si los asalariados gastan los salarios monetarios en su totalidad y así hacen también los bancos con sus beneficios netos, las empresas se encuentran en equilibrio» (Graziani, 1988b, pp-XXV-XXVI).

Si se abandona la noción de equilibrio considerado anteriormente y se supone "que, en el esquema de la economía monetaria, la posición de equilibrio no implica [necesariamente] la extinción de todas las deudas; pero admite como normal la presencia [también] de una cierta cantidad de endeudamiento de las empresas con los bancos" (Graziani, 1988a, p 126-127), el problema del cierre del circuito en equilibrio depende, 
esta vez, de la actitud de los bancos que pueden decidir si continuar financiando la actividad de producción de las empresas o, por el contrario, obligarlas a reducir sus producción, cortando sus fuentes de financiación. En este sentido, Graziani considera las acciones económicas en su dimensión temporal, presumiendo que los operadores económicos actúan en un ambiente incierto y bajo el dominio de las instituciones que prevalecen en un dado contexto histórico, según un esquema metodológico coherente con realismo histórico post-keynesiano, estudiado en el párrafo precedente.

Al centrarse en este tema en particular, los discípulos de Graziani de la escuela italiana en los últimos años se han ocupado de la individualización de los puntos de convergencia entre la teoría keynesiana de la incertidumbre y del desempleo, contenida en la Teoría General, y la teoría del dinero y de la distribución, contenida en el Tratado de la moneda. El intento de combinar el esquema del Tratado de la moneda con el de la Teoría General está vinculada a la interpretación del pensamiento continuista de Keynes, según la cual, como se ha visto en los párrafos anteriores, el Tratado de la moneda se considera como la teoría de la reproducción capitalista en equilibrio, donde el dinero se utiliza principalmente como un medio de pago, mientras que la Teoría General se concibe como la teoría de las crisis económicas que se originan en el lado de la demanda agregada, en la que el dinero se utiliza principalmente como depósito de valor (véase Fontana, 2000, Fontana , 2003 Forges Davanzati y Realfonzo, 2005; Realfonzo, 1998; Fontana y Realfonzo, 2005). En términos generales, estos estudiosos utilizan un marco metodológico que se refiere tanto a la visión circular y secuencial de la reproducción del sistema capitalista de tipo keynesiano-wickselliano (véase Forges Davanzati y Realfonzo, 2004), como al de las relaciones sociales de producción propia de Marx (véase, por ejemplo, Bellofiore 198919972004 Bellofiore y Realfonzo, 1997 e 2003), a menudo integrados con injertos de tipo schumpeteriano (véase, por ejemplo, Messori, 2004; Fumagalli y Lucarelli, 2009) o argumentos veblenianos (véase, por ejemplo, Forges Davanzati y Realfonzo, 2009; Pacella, 2009). En particular, dos elementos institucionales siempre aparecen en los modelos de Teoría monetaria de la producción de la escuela italiana de Graziani: la subordinación del trabajo al capital y el principio de atribución del poder adquisitivo a los capitalistas, que al mismo tiempo disfrutan del derecho a disponer de los medios de producción y del derecho de mando de la fuerza laboral, gracias a su capacidad de acceder a la moneda de crédito, siendo dueños de los medios de producción. Con respecto al principio de exclusividad en materia de acceso al crédito recientemente se han producido nuevos avances. Al lado del crédito para la producción, los estudiosos italianos de Teoría monetaria de la producción, en los últimos años, se han centrado también en el crédito al consumo, de acuerdo con la importancia económica de los hechos históricos que han caracterizado el mercado laboral y el de la moneda liberalizados (véase Forges Davanzati y Realfonzo, 2011; Forges Davanzati y Tortorella Esposito, 2010). En cualquier caso, el mecanismo de creación del dinero siempre sigue una secuencia lógica que ve, en principio, la creación de préstamos, seguido por la creación de los depósitos bancarios, y por último, por la creación de reservas que cubren la demanda de liquidez, de acuerdo con la ontología post-keynesiana. 
Volviendo ahora al tema del cierre en equilibrio del esquema de Graziani de Teoría monetaria de la producción, el problema conceptual más significativo que surge es el de la realización de los beneficios de las empresas, al que está conectado el de la distribución de la renta. Lo que ocurre, en efecto, es que si las empresas pudiesen recuperar el importe total del financiamiento otorgado por los bancos directamente en los mercados reales e indirectamente en los mercados financieros - se quedarían de todas maneras endeudadas con los bancos por la parte de los intereses aflorados con referencia a la financiación inicial. Relativamente a este problema con los años se han propuesto varias soluciones alternativas y competentes. En su esquema básico, Graziani relaciona la cuestión de los beneficios a las fluctuaciones de las inversiones en comparación con los ahorros, de acuerdo con un marco teórico de tipo keynesiano-wickeselliano. Por lo tanto, identificando la cuota del beneficio bruto con la cuota del producto total que las empresas deciden asignarse a sí mismas, Graziani considera la naturaleza de la tasa de ganancia como estrechamente dependiente de las decisiones unilaterales de las empresas a dividir el producto total entre el consumo y las inversiones, según proporciones diferentes de las deseadas por los trabajadores; donde, en la mejor de las hipótesis, cuando se produce el equilibrio macroeconómico, es decir, cuando las inversiones se corresponden con los ahorros, los beneficios monetarios son negativos e iguales a la deuda pendiente de las empresas, teniendo en cuenta propiamente los intereses debidos a los bancos. El esquema básico de la Teoría monetaria de la producción de Graziani, de hecho, se cierra, como se ha visto, con unas pérdidas, de modo que, mientras que por el equilibrio real la equivalencia entre las inversiones y los ahorros es suficiente, por el mercado monetario no vale la misma regla. Sólo un desequilibrio en el mercado de los bienes, debido a un exceso de las inversiones con referencia a los ahorros, puede producir un equilibrio en el mercado monetario. Por estas razones, en términos generales, los herederos de Graziani, en este tema se desvían de las enseñanzas de su maestro, abandonando el régimen de tipo wickselliano-keynesiano por uno de tipo kaleckiano-keynesiano, apoyando la tesis que la distribución de la renta depende de la capacidad de negociación de las empresas, que normalmente se refleja o en el grado de mark-up (véase Bellofiore et al, 2000. Forges Davanzati y Realfonzo, 2005) o en las actitudes conflictivas de los trabajadores y de sus reacciones en términos de productividad (véase Pacella, 2008). Con particular referencia al mecanismo de realización del surplus monetario, los estudiosos italianos de Teoría monetaria de la producción inicialmente siguieron centrándose en modelos estáticos y en un sector, enfocándose principalmente en la verdadera naturaleza de los ingresos (véase Bellofiore y Realfonzo, 1997). Más tarde, no obstante, empezaron también a prestar atención de manera explícita a la génesis de los beneficios monetarios, utilizando modelos heterogéneos, que podemos distinguir en dos diferentes corrientes de pensamiento (véase Forges Davanzati y Pacella, 2010b): la que encuentra la solución al problema de los beneficios monetarios de forma endógena al sistema y la que va en busca de la solución al mismo problema de forma exógena al sistema. El primer grupo intenta individuar una especie de «orden [...] sistémico» (Zazzaro, en Rochon y Rossi 2003) capaz de generar beneficios en el esquema básico y sin las influencias 
externas de nuevos flujos de dinero. Según este grupo, los beneficios monetarios nacerian en el sector de la producción a raíz de la quiebra de las empresas ineficientes (véase Messori y Zazzaro, 2005) o de las pequeñas empresas que sufren el racionamiento de crédito por los bancos comerciales (Forges Davanzati y Pacella, 2008); de manera que el orden sistémico sea garantizado por las mismas dinámicas del sistema capitalista. Otros (por ejemplo Zezza 2004), sin embargo, atribuyen el beneficio monetario directamente al sistema bancario, como la diferencia entre el importe total de los intereses recibidos y la cantidad total de sus costes. El segundo grupo, por fin, encuentra la solución en los flujos externos de dinero, especialmente con referencia a la deuda privada (Forges Davanzati y Tortorella Esposito, 2010), bajo la forma específica de endeudamiento de los trabajadores (ver Forges Davanzati y Pacella, 2010a) o de los rentistas (Forges Davanzati y Realfonzo, 2009).

Razonando de acuerdo con el marco teórico de este segundo grupo, la crisis económica de 2008 puede interpretarse como el resultado de un largo proceso de recesión, que se ha originado en el sector real de la economía después de la implementación de las bien conocidas políticas de la desregulación del mercado laboral, y que ha explotado con la crisis financiera internacional. Como enseña la figura 1, elaborada en los datos de la OECD, todos los Países de la Eurozona han reducido en los últimos años la protección del trabajo, donde Italia ha sido uno de los Países que más ha operado en esta dirección, reduciendo el indicador de protección del empleo (EPL) en más del 40\%; cifra ésta ligeramente superior a los datos registrados en los Países Bajos, en Finlandia, en Alemania, en Bélgica y en Grecia (por no hablar de Irlanda y Austria, que tienen mercados fuertemente liberalizados), pero inferior a los de España, Portugal y Francia.

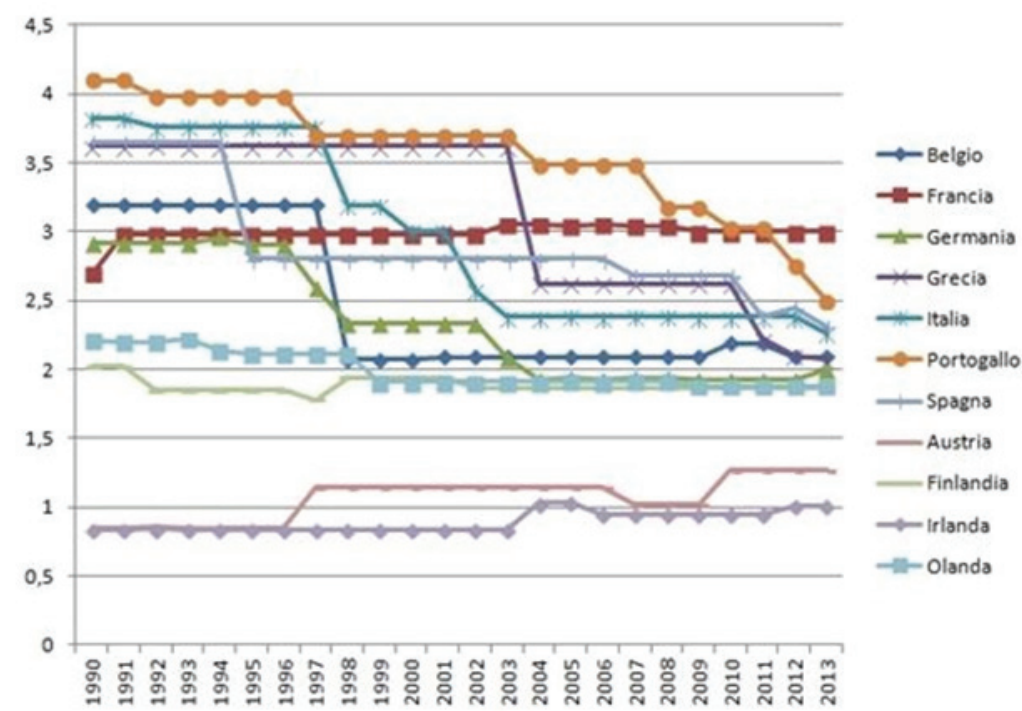

Figura 1. El indicador EPL de la OECD en la Eurozona 1990-2013 (Realfonzo y Tortorella Esposito, 2014) 
A continuación, el dato de la OECD que acabamos de analizar ha sido cruzado con con la tasa de paro calculada por EUROSTAT, a través de una simple regresión bivariada, con criterio OLS, entre la media aritmética de las variaciones porcentuales anuales de la tasa de paro y la variación absoluta del EPL, obteniendo el interesante resultado de que a pesar de la tesis dominante, de hecho, cuanto más se ha reducido en la Eurozona la protección del mercado laboral, tanto más la tasa de paro ha aumentado (ver Figura 2), con un R2 de 0.35, cuya significación estadística está garantizada por un intervalo de confianza mayor que el 5,36\% (Realfonzo y Tortorella Esposito 2014).

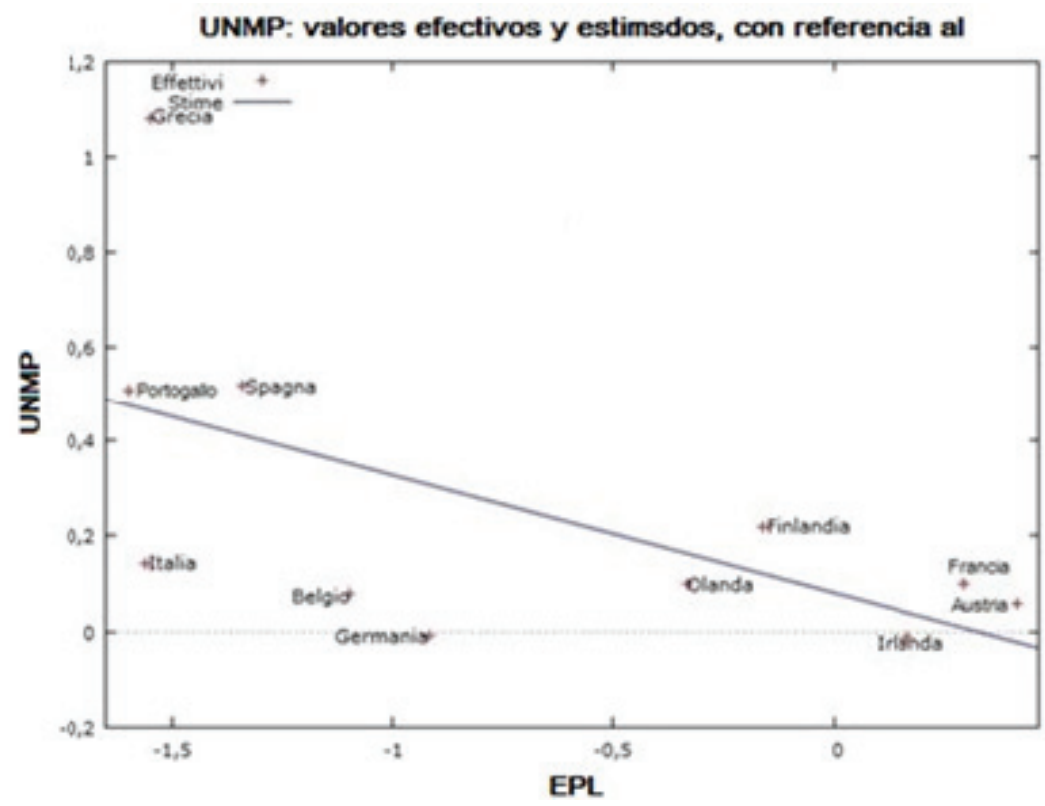

Figura 2. El Indicador EPL y el paro 1990-2013 (Fuente: nuestra elaboración a partir de los datos OECD y Eurostat)

Como se sabe, un aumento del paro produce una reducción en el poder de negociación de los trabajadores y por lo tanto una disminución de su retribución agregada. Esto con los años ha llevado a una reducción en el poder de compra de los trabajadores y a una contracción de la demanda agregada que ha empujado la economía a una situación de deuda insostenible (Pacella, Realfonzo y Tortorella Esposito 2012). Los trabajadores, en efecto, para compensar la disminución de su poder de compra han contraído deudas con los bancos para aumentar su liquidez, que, sin embargo, ha sido sólo parcial, ya que ellos han tenido que utilizarla en parte para pagar sus consumos y en parte para pagar los intereses debidos a los bancos por las deudas contraídas. Como resultado, los mismos trabajadores han expresado tener un nivel de deuda sostenible, en consonancia con un determinado nivel del tipo de interés, sobrepasado el cual, su propensión a endeudarse tiende a reducirse. Indicando 
con $\theta$ el grado de endeudamiento de los trabajadores en función del tipo de interés, es posible identificar gráficamente el tipo de interés $i^{*}$, asociado con el nivel de deuda sostenible de los trabajadores, o sea $\theta^{*}$, comparando la curva de comportamiento de los trabajadores referente al uso del crédito al consumo (EID) con sus curva de reacción a los cambios en el tipo de interés, representada por la frontera de su deuda sostenible (FSI). Siendo que, como ya se ha dicho anteriormente, con el uso creciente del crédito al consumo, la liquidez de los trabajadores crece, aunque si parte de ella está ya destinada al pago de los intereses devengados por la deuda contraída con los bancos, el nivel del tipo de interés $i^{*}$, asociado con el nivel de deuda sostenible de los trabajadores $\theta^{*}$, está fácilmente identificado por la intersección entre la curva del endeudamiento de los trabajadores y su frontera de deuda sostenible; de aquí, el tramo punteado de la curva EID indica que los trabajadores no están dispuestos a endeudarse por encima de dicho nivel del tipo de interés, para evitar encontrarse hiper endeudados con los bancos (ver Figura 3).

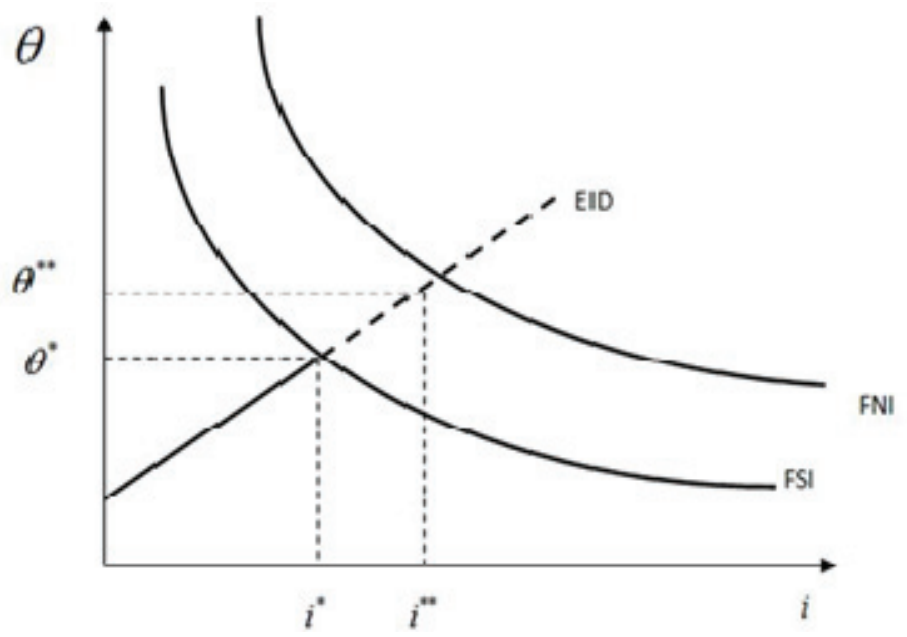

Figura 3. Endeudamiento de los trabajadores y equilibrio macroeconómico (Pacella, Realfonzo y Tortorella Espsito 2012)

De acuerdo con el marco de la Teoría monetaria de la producción que aquí estamos utilizando, las empresas, por su parte, para pagar sus deudas contraídas con los bancos para la financiación inicial de su producción, necesitan de una demanda agregada que pueda absorber toda su oferta de bienes de consumo y de títulos financieros. Sin embargo, en una economía donde la demanda agregada se reduce, por una contracción en el poder de compra de los trabajadores, el equilibrio macroeconómico, garantizado por la extinción de las deudas de las empresas con los bancos, se puede lograr, siempre que el tipo de interés se mantenga menor que o igual a aquel compatible con el nivel sostenible de la deuda de los trabajadores. En este caso, en efecto, el uso del crédito al consumo bien puede compensar la caída de la demanda agregada, garantizando el equilibrio macroeconómico y la frontera de la 
deuda sostenible de los trabajadores, manteniéndose mayor o igual a la frontera de la deuda sostenible de las empresas, representada por la curva FNI, que indica el nivel de endeudamiento de los trabajadores requerido por parte de las empresas para mantener la demanda agregada a un nivel que pueda asegurarles la extinción de la deuda contraída con los bancos para la financiación inicial de sus producción. En caso contrario, con un tipo de interés que sube por encima del nivel $i^{*}$, por ejemplo hasta al nivel $i^{* *}$, la frontera FNI se mueve hacia arriba a la derecha, ya que las empresas necesitan de un nivel de deuda sostenible de los trabajadores más alto, para pagar sus deudas a los bancos. Lo que pasa, no obstante, es que en comparación con el nuevo nivel deseado de deuda sostenible de los trabajadores por parte de las empresas $\left(\theta^{* *}\right)$ se produce un desequilibrio en el sistema económico, porque el nuevo nivel deseado $\theta^{* *}$ por parte de las empresas es mayor que el nivel $\theta^{*}$, representante del máximo grado de endeudamiento real de los trabajadores; en correspondencia de $\theta^{* *}$, de hecho, la curva FNI se cruza con la curva EID en su tramo punteado, donde, como se ha visto, los trabajadores ya no están dispuestos a endeudarse más. En la Eurozona, la reducción del index de protección del mercado laboral, con los años ha producido mecanismos recesivos como los que se han representado en la figura 3, a pesar de las estrictas políticas monetarias dispuestas por el Banco Central Europeo. Los bancos comerciales, en efecto, preocupados por el creciente endeudamiento del sistema económico en general, y por el consiguiente riesgo de caída de la liquidez, han cargado de un cierto mark up el tipo de interés definido por el BCE para los préstamos, empujándolo así a niveles más altos de aquellos compatibles con el $\theta^{*}$ de los trabajadores. Esto ha incitado los operadores económicos a endeudarse menos de lo que era necesario para mantener en equilibrio el sistema económico, produciendo efectos recesivos en el sector real de la economía, y entonces a una caída de la demanda agregada, poniendo a la Eurozona en la condición de no tener suficientes recursos para hacer frente al tsunami de la crisis financiera internacional del 2008.

\section{Conclusiones}

En este trabajo se ha tratado de ofrecer una interpretación alternativa de la crisis económica a la dominante, basada sólo en los efectos producidos por la desregulación de los mercados financieros. Adoptando aquí, en efecto, un enfoque metodológico de tipo post-keynesiano, en consonancia con la interpretación continuista del pensamiento de Keynes (ver epígrafes 1 y 2), se ha demostrado, en la tercera sección, que la crisis actual de la Eurozona se puede interpretar como el punto más alto de un ciclo económico a largo plazo, caracterizado por una creciente tendencia recesiva en el sector real de la economía, impulsada por la caída de la demanda agregada, que ha puesto a los Países de la zona euro en la condición de no estar listos para hacer frente a los efectos perturbadores de la crisis financiera que se estrelló en el 2008.

Lo que se ha analizado en particular han sido los efectos negativos producidos en la Eurozona por las políticas de flexibilización del mercado laboral. Estas políticas, en efecto, como enseñan los datos empíricos, han producido un aumento del paro; y entonces una reducción en el poder de negociación de los trabajadores, con consiguiente disminución de su retribución agregada. Esto con los años ha llevado a 
una reducción en el poder de compra de los trabajadores y a una contracción de la demanda agregada que ha empujado la economía a una situación de desequilibrio, debido a los efectos recesivos resultantes en el sector real. La caída de la demanda agregada por parte de los trabajadores, come se ha visto, ha producido con los años un endeudamiento insostenible en el sistema económico, que ha debilitado notablemente las economías de la zona Euro, en particular, causando, de un lado, la quiebra de las empresas más debilitadas y menos eficientes; y, de otro lado, la caída de la producción de las empresas más fuertes y eficientes, que mejor se han enfrentado con la crisis, con el consiguiente aumento adicional del paro.

\section{Referencias}

Arestis P. (1990) "Post Keynesianism: A New Approach to Economics", Review of Social Economy, Vol. 48, n. 3, , pp. 222-246.

Bellofiore R. (1989). "A monetary labor theory of value", Review of Radical Political Economics, Vol. 21, n. 1-2, pp. 1-26.

Bellofiore R. (ed.), (1997) "Marxian theory: the Italian debate", special issue of the International Journal of Political Economy, 1997, Vol. 27, n. 2.

Bellofiore R. \& Realfonzo R. (1997). "Finance and the Labor Theory of Value. Toward a Macroeconomic Theory of Distribution from a Monetary Perspective", International Journal of Political Economy, Vol. 27, n. 2, pp. 97-118.

Bellofiore R., Forges Davanzati G. y Realfonzo R. (2000). "Marx inside the circuit. Discipline device, wage bargaining and unemployment in a sequential monetary economy", Review of Political Economy, vol. 12, n. 1, pp. 403-417.

Bellofiore R. y Realfonzo R. (2003). "Money as finance and money as universal equivalent: re-reading Marxian monetary theory", en L. P. Rochon e S. Rossi (eds.), Modern Theories of Money: The Nature and Role of Money in Capitalist Economies, Cheltenham, UK and Northampton, MA, USA, Edward Elgar, pp. 198-218.

Bellofiore R. (2004). "As if its body were by love possessed. Abstract Labour and the Monetary Circuit: A Macro-Social Reading of Marx's Labour Theory of Value", en R. Arena y N. Salvadori (eds.), Money, Credit and the Role of the State. Essays in Honour of Augusto Graziani, Aldershot Ashgate, pp. 89-114.

Blaug M. (1968). Economic Theory in Retrospect, London, Heinemann educational books.

Boitani A. (1991). "Una nota su continuità e rottura tra il Treatise on Money e la General Theory", en J. Kregel (eds.), Nuove interpretazioni dell'analisi monetaria di Keynes, Bologna, Il Mulino, pp. 53-58.

Bossone B. (2003).“Thinking of the Economy as a Circuit", en L. P. Rochon y S. Rossi (eds.), Modern Theories of Money. The Nature and the Role of Money in Capitalist Economies, Edward Elgar Publishing Limited, UK - USA, pp. 142-172.

Costabile L. (1986). 'Metodo della scienza e teoria economica in Schumpeter. Note su "L'essenza e i principi dell'economia teorica"', Studi economici, n. 29, pp. 147168. 
Davidson P. (2003-2004). "Setting the record straight on A history of Post Keynesian economics", Journal of Post Keynesian Economics, Vol. 26, n. 2, pp. 245-272.

Delaplace G. \& Nell E. J., (1996), "Introduction: Monetary Circulation and Effective Demand", en Delaplace G. e Nell E. J. (eds.), Money in Motion. The PostKeynesian and Circulation Approaches, London, Macmillan, pp. 3-41.

Dobb M., (1973). Theories of value and distribution since Adam Smith: ideology and economic theory, Cambridge: Cambridge University Press.

Dow S. C. (1992). "Post Keynesian School", in D. Mair e A. G. Miller (a cura di), Comparative Schools of Economic Thought, Aldershot UK, Edward Elgar.

Eichner A. S. (1985). Towards a New Economics: Essays in Post Keynesian and Institutionalist Theory, London, Macmillan.

Enria A. (1991). "Alcune considerazioni sul ruolo del saggio monetario di interesse nel processo di accumulazione", en J. Kregel (eds), Nuove interpretazioni dell'analisi monetaria di Keynes, Bologna, Il Mulino, pp. 67-90.

Figuera S. (2001). Theorie monetaire dans l'economie capitaliste, L'Harmattan, Paris.

Fontana G. (2000). "Post Keynesians and Circuitists on money and uncertainty: an attempt at generality", Journal of Post Keynesian Economics, Vol. 23, n. 1, pp. 2748.

Fontana G. (2003). "Post Keynesian Approaches to Endogenous Money: a time framework explanation", Review of Political Economy, n. 3, pp. 291-314.

Fontana G. y Realfonzo R. (2005). "Introduction: The Monetary Theory of Production", en G. Fontana e R. Realfonzo (eds.), The Monetary Theory of Production. Tradition and Perspectives, London, Macmillan-Palgrave, pp. 1-16.

Forges Davanzati G. y Realfonzo R. (2004). "Labour Market Deregulation and Unemployment in a Monetary Economy", en R. Arena y N. Salvadori (eds.), Money, Credit and the Role of the State. Essays in Honour of Augusto Graziani, England USA, Ashgate Publishing Limited, pp. 65-74.

Forges Davanzati G. e Realfonzo R. (2005). "Bank Mergers, Monopoly Power and Unemployment: A Monetary Circuit Approach", en G. Fontana y R. Realfonzo (a cura di), The monetary theory of production, New York, Palgrave Macmillan, pp. 155-171.

Forges Davanzati G. y Pacella A. (2008). "Minimum wage, credit rationing and unemployment in a monetary economy",. European Journal of Economic and Social Systems, Vol. 21, n. 2, pp. 179-194.

Forges Davanzati G. y Realfonzo R. (2009). "Money, capital turnover and the leisure class. Thorstein Veblen's tips for MTP models", en J. F. Ponsot e S. Rossi (eds.), The Political Economy of Monetary Circuits, London, Palgrave, pp. 116-137.

Forges Davanzati G. y Pacella A. (2010a). "Emulation, indebtedness and income distribution: a monetary theory of production approach ", Intervention. European Journal of Economics and Economic Policies, Vol. 7, n.1, pp. 145-165.

Forges Davanzati G. y Pacella A. (2010b). "The effect of unemployment benefits on income distribution in a monetary economy", Articulo presentado en la VII Storep Conference, Trento. 
Forges Davanzati G. \& Tortorella Esposito G. (2010). "Low Wages, Private Indebtedness, and Crisis. A Monetary-Theory-of-Production Approach", European Journal of Economic and Social Systems, Vol. 23, n. 1, pp. 25-44.

Forges Davanzati G. \& Realfonzo R. (2011). "Low Wages, Consumer Credit and the Crisis: A Monetary Theory of Production Approach", en E. Brancaccio y G. Fontana (eds.), The Global Economic Crisis. New Perspectives on the Critique of Economic Theory and Policy, New York, Routledge, pp. 144-163.

Fumagalli A. \& Lucarelli S. (2009). "Cognitive capital as financial economy of production", Articulo presentado en el Fourth Bi-Annual Conference "The Financial and Monetary Crisis: Rethinking Economic Policies and Redefining the architecture and government of international finance", Université de Bourgogne, Laboratoire Economie Gestion Dijon, France, Diciembre.

Furness W. H. (1910). The Island of Stone Money: Uap of the Carolines, Philadelphia, J. B. Lippincott Co., cap. 7, pps. 94-106.

Garegnani P. (1979). Valore e domanda effettiva: Keynes, la ripresa dell'economia classica e la critica ai marginalisti, Torino, Einaudi.

Graziani A. (1977). "Introduzione", en Schumpeter J. A., Il processo capitalistico. Cicli economici, Torino, Boringhieri, pps. 7-33.

Graziani A. (1984). "The Debate on Keynes' Finance Motive", Economic Notes, Vol. 13, n. 1, pp. 5-32.

Graziani A. (1985). "Commento ad Alvaro Cencini”, Studi Economici, n. 25, pp. 131141.

Graziani A. (1987). “Keynes’ Finance Motive”, Economie et Sociétés, Série Monnaie et production, n. 9, pp. 23-42.

Graziani A. (1988a). "La teoria del circuito e la Teoria generale di Keynes", en Messori M. (eds.), Moneta e Produzione, Torino, Giulio Einaudi Editore.

Graziani A. (1988b). "Il circuito monetario", en M. Messori (eds.), Moneta e Produzione, Torino, Giulio Einaudi Editore.

Graziani A. (1994). "Introduzione", en A. Graziani, La teoria monetaria della produzione, Banca popolare dell'Etruria e del Lazio/Studi e Ricerche, pp. 13-31.

Graziani A. (2003). "Introduction", en A. Graziani, The Monetary Theory of Production, Cambridge, Cambridge University Press, pp. 1-32.

Hamouda O. F. \& Harcourt G. C. (1988). "Post Keynesianism: From Criticism to Coherence?", Bulletin of Economic Research, vol. 40, n. 1, pp. 1-33.

Harcourt G. C. (1985). "Post Keynesianism: Quite Wrong and/or Nothing New", in P. Arestis e T. Skouras (a cura di), Post Keynesian Economic Theory: A Challenge to Neo-Classical Economics, Sussex, Wheatsheaf Book, .

Harcourt G. C. (1988). "Post Keynesian Economics", en J. Eatwell, M. Milgate and P. Newman (eds.), The New Palgrave: A Dictionary of Economics, London, Macmillan, pp. 924-928.

Hawtrey R. G. (1919). Currency and Money, London, Longsman, Green and Co.

Hodgson G. (1989). "Post Keynesian and Institutionalism: The Missing Link", in J. Pheby (a cura di), New Directions in Post Keynesian Economics, Aldershot UK, Edward Elgar, , pp. 94-123. 
Holt, R.P.F. (1997). "Post Keynesian School of Economics", in T. Cate (a cura di), An Encyclopedia of Keynesian Economics, Cheltenham, Edward Elgar,.

Keynes J. M. (1921). Treatise on Probability, London, Macmillan,.

Keynes J. M. (1932). Trattato della moneta, Milano-Roma, Edizioni Fratelli Treves, , vol. 1.

Keynes J. M. (1936). The General Theory of Employment, Interest and Money, London, McMillan.

Keynes J. M. (1937). "The General Theory of Employment", The Quarterly Journal of Economics, vol. 51, n. 2, p. 212-223.

Keynes J. M. (1979). The Collected Writings of J. M. Keynes, Macmillan, London, Vol. XXIX.

King J., A (2002). History of Post Keynesian Economics Since 1936, Cheltenham, Edward Elgar.

Kregel J. A. (1976). "Methodology in the Face of Uncertainty: The Modelling Methods, of Keynes and Post-Keynesians", The Economic Journal, vol. 86, n. 342, pp. 209-225.

Lunghini G. (1988). Equilibrio, Torino, Boringhieri.

Lunghini G. (1990). "Introduzione”, en J. A. Schumpeter, Storia dell'analisi economica, Torino, Bollati Boringhieri, , pp. XXVII - XXXII.

Messori M. (2004), "Credit and Money in Schumpeter's Theory", en R. Arena y N. Salvadori (eds.), Money, Credit and the Role of the State. Essays in Honour of Augusto Graziani, Aldershot Ashgate, pp. 175-202.

Messori M. and Zazzaro A. (2005). "Single-period analysis: financial markets, firms' failure and closure of the monetary circuit", in G. Fontana y R. Realfonzo (eds.), The monetary theory of production, New York, Palgrave Macmillan, pp. 111-123.

Pacella A. (2008). "The effects of labour market flexibility in the monetary theory of production", Metroeconomica, Vol. 59, n. 4, pp. 608-632.

Pacella A. (2009), We Have What We Are. Veblen and The Conflictual Nature of Monetary Economies, Saarbrucken, Germany, VDM Verlag Dr. Muller e.K.

Pacella A. and Tortorella Esposito G. (2012). "The Legacy of Augusto Graziani and Luigi Lodovico Pasinetti in the Post Keynesian Research Tradition", en S. Lucarelli y M. Passarella (eds.), New Research Perspectives in the Monetary Theory of Production, Bergamo, Sestante edizioni, pp. 23-38.

Pacella A., Realfonzo R. y Tortorella Esposito G. (2012). "Crisis and Central Banks: a Circuitist Approach", Articulo presentado en la 53a Reunión cientifica anual de la Societá Italiana degli Econmomisti, ottobre.

Pasinetti L., (1974). Sviluppo economico e distribuzione del reddito, Bologna: Il Mulino.

Pasinetti L. (1991). "Dal Treatise on Money alla General Theory: continuità o rottura?", en J. Kregel (ed.), Nuove interpretazioni dell'analisi monetaria di Keynes, Bologna, il Mulino, pp. 43-51.

Pasinetti L. (1999). "J.M. Keynes's revolution - the major event of twentieth century economics?", en L. Pasinetti and B. Schefold (eds.), The impact of Keynes on economics in the 20th century, Cheltenham, Edward Elgar, pp.3-15. 
Patinkin D. (1956). Money, Interest and Prices, New York, Harper \& Row.

Patinkin D. (1975). "The collecting Writings of J. M. Keynes: from the Tract to the General Theory", The Economic Journal, Vol. 85, n. 338, pp. 249-271.

Realfonzo R. (1998). Money and Banking: Theory and Debate (1900-1940), Cheltenahm and Northempton, Edward Elgar.

Realfonzo R. y Tortorella Esposito G. (2014). "Gli insuccessi della liberalizzazione del lavoro a termine", Economia e politica, 13 maggio, www.economiaepolitica.it.

Robertson, D. H. (1926). Banking Policy and the Price Level, London, King.

Robertson D. H. (1935). "La Moneta", en G. U. Papi (eds.), Mercato monetario, collana di economisti stranieri e italiani, Vol. VIII, Torino, U.T.E.T., pp. 235-355.

Robertson D. H. (1993). "Banking Policy and the Price Level", in L. Costabile (a cura di), Politica bancaria e livello dei prezzi. Con altri scritti sulla moneta, Napoli, ESI.

Rochon L. P. \& Rossi S. (2003). "Introduction”, en L. P. Rochon e S. Rossi (eds.), Modern Theories of Money. The Nature and the Role of Money in Capitalist Economies, Edward Elgar Publishing Limited, UK - USA, pps. XX-LVI.

Samuelson P. A. (1968). "What Classical and Neo-Classical Monetary Theory Really Was", Canadian Journal of Economics, n. 1, pp. 1-15.

Sawyer M. (1988). Post Keynesian Economics, Aldershot UK, Edward Elgar.

Schlesinger K. (1914), Teorie der Geld und Kreditwirtshaft, Munich, Duncker \& Humblot.

Schumpeter J. A. (1990). Storia dell'analisi economica, Torino, Bollati Boringhieri.

Seccareccia M. (2004).“Aspects of a new conceptual integration of Keynes's Treatise on Money and the General Theory: Logical time units and macroeconomic price formation", in R. Arena e N. Salvadori (a cura di), Money, Credit and the Role of the State. Essays in honour of Augusto Graziani, Aldershot, Ashgate, pp. 285-312

Zazzaro A. (1995). "La specificità delle banche. Teorie a confronto da una prospettiva schumpeteriana", Studi economici, n. 55, pag. 113-151.

Zazzaro A. (2003). "How Heterodox is the Heterodoxy of Monetary cicuit Theory? The Nature of Money and the Microeconomics of the Circuit", en L. P. Rochon y S. Rossi (eds.), Modern Theories of Money. The Nature and the Role of Money in Capitalist Economies, Edward Elgar Publishing Limited, UK - USA, pp. 219-245.

Zezza G. (2004). "Some simple, consistent model of the monetary circuit", The Levy Economics Institute, , working paper n. 405. 